\title{
Procedure for the Transboundary Environmental Impact Assessment of Contemplated Investment Projects in the Polish Legal System
}

\author{
Andrzej Harat ${ }^{1 *}$, Andrzej Jaguś ${ }^{2}$ \\ 1 Institute of Civil Engineering, University of Bielsko-Biala, Willowa 2, 43-309 Bielsko-Biała, Poland \\ 2 Institute of Environmental Protection and Engineering, University of Bielsko-Biala, Willowa 2, 43-309 Bielsko- \\ Biała, Poland \\ * Corresponding author's e-mail: aharat@ath.bielsko.pl
}

\begin{abstract}
In the process of implementing a construction project, it is necessary to meet numerous requirements imposed on investors by regulations related to broadly understood environmental protection, which are significant for the vast majority of investment processes. For obvious reasons, the environment, understood as all natural elements, is not subject to geopolitical division principles. Therefore, the issue of international cooperation between states in the field of environmental protection is becoming increasingly important. One of its major tools is the procedure for transboundary environmental impact assessment in the Polish legal order. The article presents regulations applying to the strategic environmental impact assessment and verification of the environmental effects of project implementation. The complex nature of the indicated regulations, as well as their nonuniform application by entities issuing administrative decisions may directly contribute not only to delays in implementing an investment project, but also to a significant increase in its costs. It should also be remembered that strict compliance with these requirements is a necessary condition for the participation of Community funds in the implementation of a specific project.
\end{abstract}

Keywords: transboundary environmental impact, investment process, environmental proceedings

\section{INTRODUCTION}

The implementation of an investment project is a complicated and difficult process. In addition to technical issues, it requires the fulfilment of numerous legal requirements, which result directly from statutory regulations or from individual administrative decisions issued with respect to investors by competent public administration authorities. The matter of utmost importance in the process of implementing a construction project is the obligation to meet numerous requirements imposed on investors by regulations related to broadly understood environmental protection. Environmental impact assessment procedures should be considered a basic legal instrument in this respect. Environmental Impact Assessment (EIA) is arguably the world's most widespread environmental policy tool (Fonseca et al. 2017) and is now recognized as a global norm in international environmental law (Yang 2018). EIA is understood as a multidisciplinary tool that attempts to predict the various impacts a project will have upon its surroundings, including the biophysical, social and health environments (Loomisa and Dziedzic 2018). Despite its subjective nature (Cashmore et al. 2008), most authors agree that EIA effectiveness is multidimensional and plural in nature (Rozema and Bond 2015).

According to data collected by the European Commission, approximately 16,000 EIAs are conducted each year across the EU-27 for different types of projects, including infrastructure (i.e., energy, transport, waste and wastewater treatment) and industrial and urban development (Larrey-Lassalle et al. 2017). The basic legal act regarding this issue in Polish law is the Act on Making Available Information about the 
Environment and its Protection, the Public's Participation in Environmental Protection, as well as on Environmental Impact Assessments of 3 October 2008 ("AEIA"). The regulations contained in the text of the above Act are the result of the implementation of Community legal provisions, which include: Directive 2011/92/EU of 13 December 2011 on the assessment of the effects of certain public and private projects on the environment (Official Journal of the EU L. 2012.26.1) and Directive 2001/42/EC of 27 June 2001 on the assessment of the effects of certain plans and programs on the environment (Official Journal of the EU L. 2001.197.30). Both Community and Polish legal regulations adopt a similar division of environmental impact assessment procedures. Consequently, there are the following: strategic environmental impact assessment, environmental impact assessment of projects, environmental impact re-assessment of projects, area impact assessment Natura 2000 and transboundary environmental impact assessment, which procedure is the subject of the considerations contained in this article. There is no doubt that a particular investment project or the implementation of a policy, strategy or program may directly or indirectly affect the territory of another country. For this reason, international cooperation regarding environmental issues is a matter of utmost importance. The literature emphasizes that its task is to create compromise solutions, combining the principle of sovereignty of states, which is the basis of international law, with the necessity of using the shared environment and the need for socio-economic development (Ciechanowicz-McLean 2015).

\section{TRANSBOUNDARY ENVIRONMENTAL IMPACT ASSESSMENT IN POLISH LAW}

Large-scale industrial or infrastructure projects frequently pose significant environmental impacts which are mostly not limited to the local scale. These are determined by the implementation of an environmental impact assessment (Albrecht 2008). Issues related to environmental impact in the Polish legal order are subject to the regulation of Section VI of AEIA (articles 104-120), as well as external sources of law, i.e. in particular the Convention of 25 February 1991 on transboundary environmental impact assessment and possible bilateral agreements, i.e. bilateral agreements concluded between the
Republic of Poland and another state. A bilateral agreement with a clear definition of the authorities, their roles and tasks, organizations of public participation, and other aspects will diminish the pressures around the application (De Boer 1999). It is worth noting that the rules of conduct contained in the latter, and, in particular, the ones regarding dispute settlement may differ from those arising from multilateral agreements. A central component of EIA processes and one that strongly affects quality performance is scoping - deciding what issues and impacts are included or excluded in an EIA and how these are addressed (Kagstrom 2016). Proceedings in the discussed area may be conducted as part of the analysis of transboundary environmental impact in the field of strategic environmental impact assessment or environmental assessment of the effects of a project. The subject of the second of these proceedings may be any contemplated investment project the implementation of which is likely to have a transboundary impact. The common feature of both procedures is the approach to the issue of administration bodies competence, which is different than in the case of other types of environmental impact assessments. This is, of course, due to their specificity, involving the need to conduct proceedings with the participation of another state's authorities. For obvious reasons, these proceedings should not be conducted by the bodies of local government units or the Regional Director for Environmental Protection (RDEP). The competent body in the case of this type of proceedings in the Polish legal order is the General Director for Environmental Protection (GDEP), who makes appropriate arrangements with a foreign country authority. The type and scope of the competence of the latter are determined by the internal legal regulations of a given country, which are usually confirmed by a bilateral agreement.

\section{PROCEDURE FOR THE STRATEGIC ENVIRONMENTAL IMPACT ASSESSMENT}

The legal grounds for initiating proceedings on the assessment of transboundary impacts conducted as part of the strategic environmental assessment are set out in the provisions of Article 104 clause 1 and 2, in connection with art. 46 and 47 of AEIA. Consequently, the basic condition to be considered is the possibility of a significant transboundary environmental impact, originating on the 
territory of the Republic of Poland, as a result of the implementation of documents the catalogue of which is included in art. 46 and 47 of AEIA. The latter relate in particular to national, provincial and municipal acts on spatial policy (the concept of spatial development of the country, the voivodship spatial development plan, the study of conditions and directions of spatial development, the local spatial development plan), regional development strategies, as well as all kinds of documents containing plans or programs of infrastructure projects related to a specific sector of the economy, which have been adopted by state and local government administration bodies. A relevant request to initiate this type of proceedings may be submitted by both the administrative body developing a specific draft policy, strategy or plan, as well as at the request of the country whose territory may be affected by the implementation of a specific project. In both cases indicated above, the authority conducting the proceedings is GDEP. The flowchart of the strategic environmental assessment procedure has been presented in Figure 1.

Statutory regulations (Article 113(1) of AEIA) expressis verbis require entities that prepare documents to immediately notify the General Director for Environmental Protection of the possibility of a transboundary impact as a result of implementing a given strategy or plan. Beside the notification, it is also necessary to provide a draft document together with an environmental impact forecast, which, in turn, obliges GDEP to immediately communicate this fact to the competent authorities of the country affected by a potential transboundary impact. This obligation also involves the transfer of relevant, previously received documentation. It is worth noting that this obligation arises not only from AEIA regulations, but also from Community legislation. Obviously, the latter applies to the Member States of the European Union. Its analogous application to other countries may result from a bilateral international agreement. Interestingly, the Act (Article 113(2)) does not require the entire documentation to be submitted in the official language of a foreign country. It is necessary to translate only those fragments that will enable conducting a transboundary impact assessment. The further course of the proceedings depends on the stance expressed by the foreign state authority in response to the GDEP notification. Together with the latter, this authority sets a deadline for a given country's response regarding its interest in participating in the proceedings related to transboundary

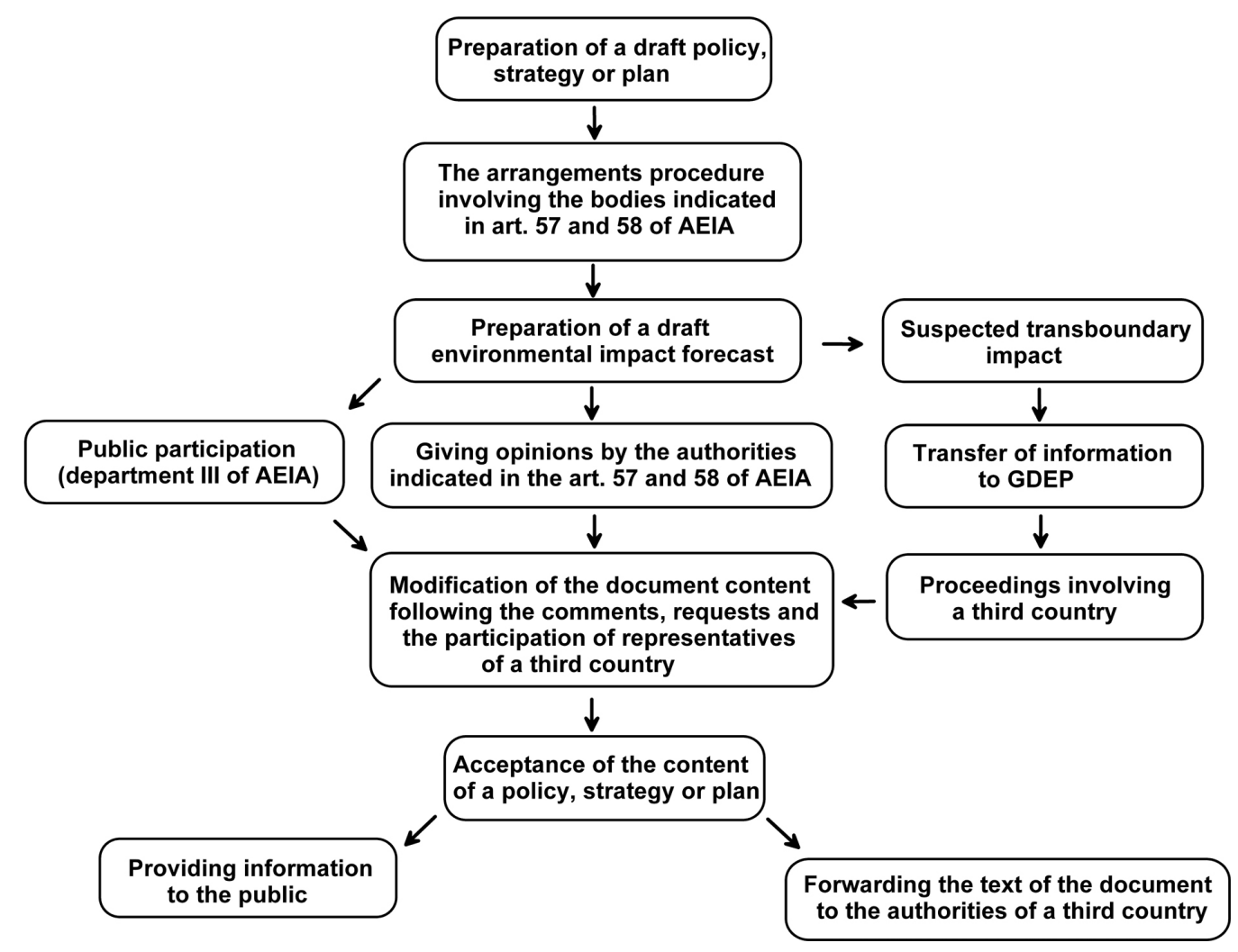

Figure 1. Flowchart of the strategic environmental assessment procedure 
environmental impact. The further course of the proceedings is determined by the answer given. In the event the authority of another country notifies the General Director that it is interested in participating in the proceedings, the latter is obliged to make relevant arrangements concerning the dates of the procedure, taking into consideration the necessity to hold public consultations, as well as making sure that other bodies and institutions will take part in the proceedings. It should be noted that GDEP is obliged to make appropriate arrangements with both the entity conducting the strategic environmental assessment and the authority of another country.

The analysis of the provisions of the Act clearly demonstrates that the General Director for Environmental Protection in the described proceedings fulfils primarily a coordination function. Such a conclusion can be drawn on the basis of regulations regarding cross-border consultations, which should be considered the most important element of the ongoing proceedings. AEIA, in the content of art. 115(1), clearly indicates that the procedure for international arrangements is in principle carried out by the body conducting the strategic environmental assessment. At the same time, pursuant to the provisions of the Act, they can be taken over by the General Director if he deems it appropriate due to the importance and complexity of the case. The purpose of the consultation procedure is to eliminate or reduce the transboundary impact. It should be emphasized that the position of foreign state authorities presented in the procedure is not binding on Polish public administration bodies, as it is expressed only in the form of opinions. However, it is important for finishing the proceedings related to the adoption of a strategic environmental impact assessment in the Polish internal legal order. It results directly from the regulation of art. $116 \mathrm{sec}-$ tion 2 of AEIA, which explicitly emphasizes that the document should not be adopted before the conclusion of the proceedings regarding transboundary environmental impact.

In the final stage of the described procedure, GDEP forwards the documentation required by law to the competent authorities of another country. It should include a strategic environmental impact assessment, with particular regard to the part that will enable the other state to find out how the results of the transboundary environmental impact procedure were considered and taken into account when adopting the document.
A similar procedure connected with the assessment of environmental effects may also be initiated in relation to plans and programs, as well as investment projects planned outside the territory of the Republic of Poland, where the effects of their implementation may affect Poland. Similarly to the case described above, the General Director for Environmental Protection is the entity responsible for coordinating activities and intermediating in the process of consultation with foreign state authorities. Having received documents containing this type of information, GDEP is obliged to immediately pass it on to the Regional Director for Environmental Protection responsible for the area of a potential transboundary impact. Such a solution should be considered appropriate, given the need to conduct a thorough analysis of the submitted documentation, taking into account regional specificities. It is run by RDEP in order to establish the legitimacy of initiating the proceedings. The further course of the proceedings in procedural terms is similar to the assessment of the transboundary environmental effects of documents prepared on the territory of Poland. In the event the Regional Director deems Poland's participation in the proceedings necessary, he is obliged to immediately communicate this fact to GDEP, who, in turn, has an obligation to inform the authorities of another country. If an entity declares its readiness to join the proceedings, it has to submit information regarding the planned project to the General Director. Next, the presented data must be passed on to RDEP, who is obliged to carry out a number of activities. Pursuant to the provisions of Art. 119 section 1 and 2 of AEIA, they involve in particular conducting public consultations, if necessary, also seeking the opinion of other bodies and institutions, and next, preparing a draft stance of GDEP on the document being the subject of the analysis, which is then forwarded to another country. Of course, the submitted RDEP arrangements are not legally binding on the opinion of the General Director, although it is usually based on them in practice. The final stage of the described procedure is feedback that the authorities of another state send to GDEP, the most important element of which is the decision on the project, plan or strategy with particular focus on the reduction of transboundary impacts. The General Director is obliged to forward the received stance of RDEP responsible for the area of a potential transboundary environmental impact. The statutory obligation of the latter, resulting from art. 120(2) of 
AEIA, is to make this fact public and to provide information on the possibilities of becoming acquainted with its content.

\section{PROCEDURE FOR THE TRANSBOUNDARY IMPACT OF PROJECTS}

Pursuant to the provisions of art. 104 clause 1 of AEIA, the subject of transboundary proceedings relating to the environmental impact assessment of projects are decisions that may result in this type of impact. In addition, the legislator specifies the catalogue of administrative acts with respect to which it allows this type of procedure to be conducted. Consequently, it should be stated that the described procedure relates primarily to decisions regarding environmental conditions. It may also apply to other types of decisions including building permits, permits for road investments or public airports if the environmental impact assessment was not carried out in the previous proceedings related to the issue of decisions on environmental conditions. The flowchart of the procedure regarding the transboundary impact of projects has been presented in Figure 2.

The decision on conducting the proceedings is taken by the authority competent to issue a transboundary environmental impact decision. As a rule, this entity is the Regional Director for Environmental Protection. In the case of contemplated projects included in the group of enterprises that can always have a significant impact on the environment, potential problems of transboundary impacts should be considered by analyzing the project information card submitted by the investor, because the regulation of art. 69 clause 1 and 2 of AEIA clearly indicates that if there is a possibility of a transboundary environmental impact of a given investment project, he is obliged to submit an application for determining the scope of the relevant report. On the other hand, in the case of contemplated projects which have been found to hold the potential for exerting a significant impact on the environment, the proceedings in relation to transboundary impacts depend on the administrative body's decision regarding the necessity and scope of the report on the environmental impact assessment.

Apart from RDEP, the request to conduct the proceedings in question can be made by another EU Member State. It should be emphasized that the entity conducting the proceedings is bound by this type of request and must take into account potential transboundary impacts while examining the circumstances of the case.

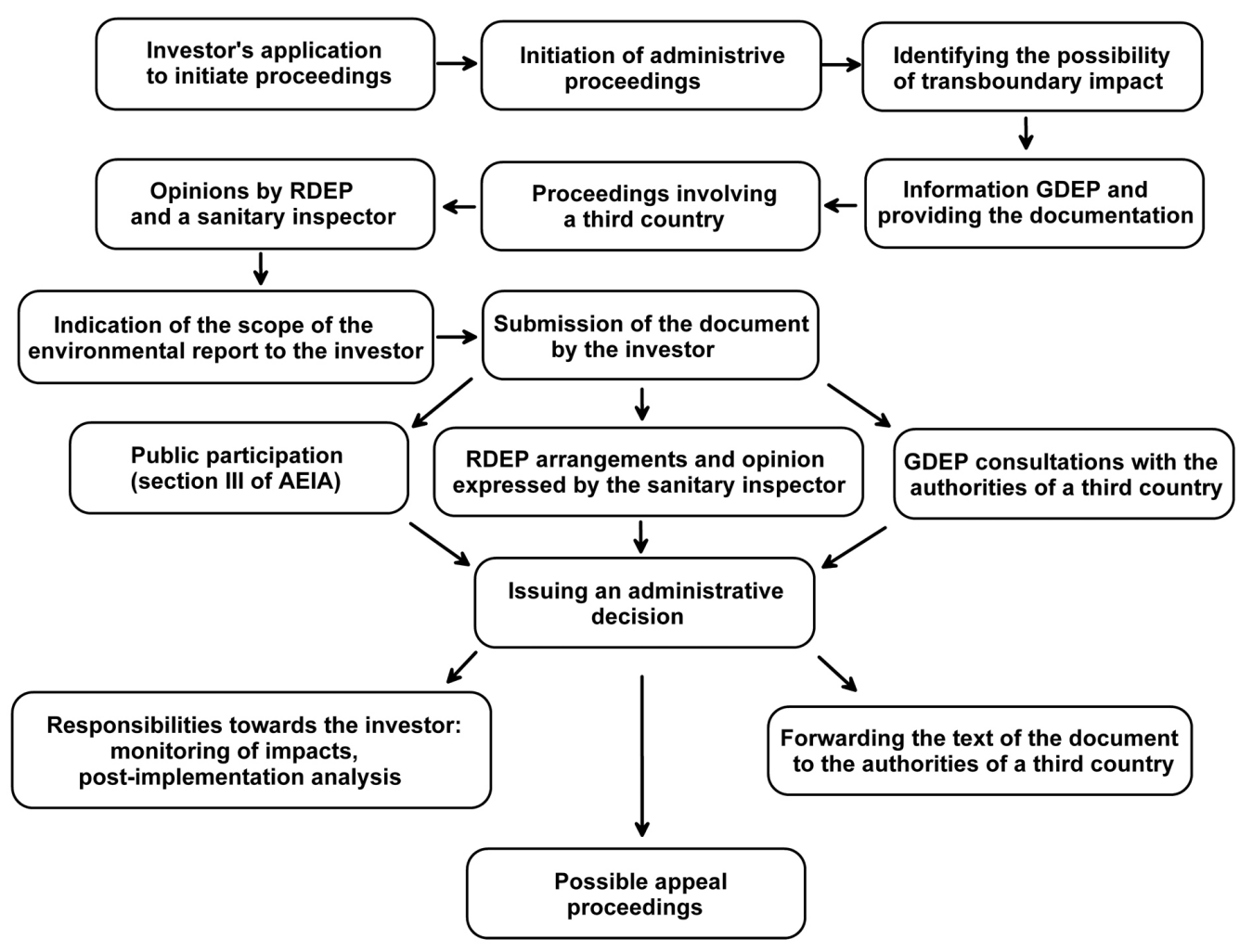

Figure 2. Flowchart of the procedure regarding the transboundary impact of projects 
The consideration of possible transboundary impacts in the course of the ongoing environmental impact assessment procedure is in the form of a provision. Of course, one can lodge an ordinary appeal against the latter in the form of a complaint. At the same time, upon the issue of the decision, pursuant to the provisions of Art. 108 section 1 AEIA, the authority determines the scope of documentation necessary to conduct the procedure, and then imposes the obligation to prepare it on the organizational unit reporting the intention to implement the investment. The said obligation usually involves translating the documentation into the official language of the country affected by the potential transboundary impact. The documentation submitted by the entity should contain, in particular, an information card for the project and a part of the report on the environmental impact of the project that will allow another country to assess the potential transboundary impact.

As in the case of proceedings related to strategic environmental assessment, the entity coordinating activities in the field of cooperation with relevant foreign state authorities is the General Director for Environmental Protection. Having received information about a potential transboundary impact of a project, GDEP notifies the state on the territory of which the impact may occur by submitting the documentation prepared and translated by the investor as required by law. The reaction of the authorities of a foreign state to the submitted notification may be twofold. It may not express interest in participating in the proceedings, which makes them irrelevant, or declare its intention to participate, which necessitates agreeing the dates of individual stages of the proceedings, taking into account the need to ensure the participation of relevant entities and the society of the country concerned. The key element of the conducted proceedings are international consultations aimed at establishing measures to eliminate or reduce the transboundary environmental impact. As a rule, it is carried out by an administrative body conducting the environmental impact assessment of the project, unless GDEP, considering the importance or complexity of the case, decides that it is necessary to take over this duty. As part of the proceedings, representatives of the country affected by a potential transboundary impact are entitled to submit comments and motions. AEIA regulations (Article 111 paragraph 2) require entities conducting proceedings to take them into account when issuing an administrative decision. Its issuance results in the need to notify the authorities of the state participating in the procedure, which is the responsibility of GDEP. When submitting the document regarding the settlement of the case, this authority should additionally submit the decision translated by the applicant in the part which shows the other state how the results of the transboundary environmental impact proceedings were taken into account when issuing the decision.

It is worth noting that the resolution of the issue discussed is relevant to the implementation of the contemplated investment as a whole. This is due to the fact that the decision on the implementation of the project cannot be issued before the end of the procedure relating to transboundary impacts.

\section{CONCLUSIONS}

In recent years there has been a growing interest in issues related to the necessity of intensifying international cooperation in the field of environmental protection. It is particularly facilitated by actions taken by the United Nations or EU Member States. A good example of an institutionalized form of international cooperation can also be the procedure for transboundary environmental impact assessment discussed in this article.

It seems that the need to include this type of legal instrument as an element of an investment project assessment results from the specific nature of the conducted procedure, which, as a rule, is conducted on the basis of the provisions of the Code of Administrative Procedure in force in the country having jurisdiction over the place of the contemplated investment project, with the participation of natural or legal persons residing or having their registered office on the territory of a given country.

At the same time, it should be taken into account that the effects of planned activities may often be transboundary in nature. Taking into account this type of impact results in allowing foreign entities to participate in the environmental procedure as its party, as well as granting them the right to submit applications and evidence to support them. This allows minimizing the negative environmental effects of the investment activities carried out at the design stage.

It can therefore be concluded that the procedure of transboundary environmental impact 
assessment is an excellent example of the practical implementation of the standard formulated in art. 191 paragraph 2 of the Treaty on the Functioning of the European Union, according to which the Union's environmental policy is based on the precautionary principle and the principle of preventive action. EIA is therefore an essential tool to improve the quality of information which is presented to decision makers and which guide them in view of taking decisions that minimize adverse impacts on the environment (Hunter et al. 2010).

\section{REFERENCES}

1. Albrecht E. 2008. Implementing the Espoo Convention in transboundary EIA between Germany and Poland. Environmental Impact Assessment Review, 28, 359-365.

2. Cashmore M., Bond A. Cobb D. 2008: The role and functioning of environmental assessment: theoretical reflections upon an empirical investigation of causation. Journal of Environmental Management, 88(4), 1233-1248.

3. Ciechanowicz-McLean J. 2015. Prawo ochrony środowiska jako kompleksowa dziedzina prawa ustawa organiczna. In: P. Korzeniowski (ed.) Zagadnienia systemowe prawa ochrony środowiska. Publishing House of University of Lodz (in Polish), pp. 55-66, online available at: http://dspace. uni.lodz.pl:8080/xmlui/handle/11089/18056 [Accessed 20 Jul. 2020].
4. De Boer J.J. 1999. Bilateral agreements for the application of the UN-ECE convention on EIA in a transboundary context. Environmental Impact Assessment Review, 19, 85-98.

5. Fonseca A., Sánchez L.E., Ribeiro J.C. 2017. Reforming EIA systems: A critical review of proposals in Brazil. Environmental Impact Assessment Review, 62, 90-97.

6. Hunter D., Salzman J., Zaelke D. 2010: International Environmental Law and Policy. Fourth Edition (University Casebook). West Academic, Foundation Press, Minnesota, US.

7. Kagstrom M. 2016. Between "best" and "good enough": How consultants guide quality in environmental assessment. Environmental Impact Assessment Review, 60, 169-175.

8. Larrey-Lassalle P., Catel L., Roux P., Rosenbauma R., Lopez-Ferber M., Junqua G., Loiseau E. 2017. An innovative implementation of LCA within the EIA procedure: Lessons learned from two Wastewater Treatment Plant case studies. Environmental Impact Assessment Review, 63, 95-106.

9. Loomisa J.J., Dziedzic M. 2018. Evaluating EIA systems' effectiveness: A state of the art. Environmental Impact Assessment Review, 68, 29-37.

10. Rozema J.G., Bond A.J. 2015. Framing effectiveness in impact assessment: discourse accommodation in controversial infrastructure development. Environmental Impact Assessment Review, 50, 66-73.

11. Yang T. 2018. The emergence of the environmental impact assessment duty as a global legal norm and general principle of law. Hastings Law Journal, 70(2), 525-572. 